\title{
Periodontal Therapy of the Future-Many Challenges and Opportunities
}

\author{
Patrick R. Schmidlin* \\ Clinic of Conservative and Preventive Dentistry, Center of Dental Medicine, Faculty of Medicine, University of Zurich, Zurich, \\ Switzerland
}

Keywords: periodontitis, diagnostics, peridontal disease, periodontal therapy, research

\section{PERIODONTAL RESEARCH: THE CORNERSTONE OF HEALTH}

Roughly $50 \%$ or more of the word population suffer from a form of periodontitis and about 750 million people suffer from a severe form (1). This number is higher than, for example, diabetes, which affects around 450 million adult patients (2). According to an estimate of WHO in 2018, the total number of people living within 5 years of cancer diagnosis, the so-called 5-year prevalence, is estimated at 43.8 million (3). In view of these figures, periodontitis is indeed an important topic. Especially if one considers the clinical connections with diabetes or other systemic diseases $(4,5)$. The prevention and therapy of this inflammatory disease, which is mostly caused by bacteria, must be intensified and intensively fought from a health policy perspective.

\section{OPEN ACCESS}

Edited by:

Moritz Kebschull,

University of Birmingham,

United Kingdom

Reviewed by:

Pia-Merete Jervøe-Storm,

University of Bonn, Germany

*Correspondence:

Patrick R. Schmidlin

patrick.schmidlin@zzm.uzh.ch

Specialty section: This article was submitted to Periodontics,

a section of the journal Frontiers in Dental Medicine

Received: 20 January 2020 Accepted: 13 May 2020

Published: 01 June 2020

Citation:

Schmidlin PR (2020) Periodontal

Therapy of the Future-Many

Challenges and Opportunities.

Front. Dent. Med. 1:2.

doi: 10.3389/fdmed.2020.00002
"BIO"

"BIO" and stands for the Greek word Bioç "Life" and has received an important meaning in language and life and is far more than a powerful word stem. A healthy lifestyle is more than ever in demand and on everyone's lips. The latter actually also contains a large mass of "bio"-especially in the form of biofilms.

A sterile oral cavity would probably not be realistic and probably not even desired by nature. There are good reasons to socialize humans and other animals with a variety of bacteria and, above all, to colonize mucous membranes and skin in a targeted manner. While there is no doubt that a healthy microbiome is necessary for the intestine to be able to "go about its daily business," many people wonder why we have an oral flora (6).

What is certain is that bacteria are numerically superior to host cells and have been with us for a long time in both good and bad times: Microbiological studies on tartar from different periods of human history prove this: The diversity of bacteria in humans has always been large and already in the Stone Age it was very diversified among hunters and gatherers. However, paropathogenic germs such as $P$. gingivalis were not yet detectable. Above all, social "revolutions" such as those during the Neolithic or industrialization periods led to bacterial upheavals-not only in a positive sense-in the carrier and its microbiological load and thus to pathological leaps in development (caries and periodontitis) (7).

\section{BIO-FILM}

Biofilms belong to us and to the oral ecosystem (8). This seems to be the state of error-to be clear. But "healthy" it must be, i.e., symbiotic. Let's take the Koala as an example. Especially with these cute balls of wool, the intestines play an important role. It is specific bacteria that enable the digestion of eucalyptus leaves. If the intestinal flora is disturbed, the nutritional basis and existence 
of these animals is severely disturbed (9). This happens, for example, after chlamydia infections. These are treated with antibiotics and Lonepinella koalarum, a bacterium that plays an important role in digestion (tannin degradation), is also affected. Alternative treatments are therefore urgently sought in order not to endanger the populations. Stool transplants have already been mentioned and carried out as an option.

Concepts are therefore in demand which not only reduce but also modify pathogenic biofilms and allow a permanent biological balance with the host. The "Guided Biofilm Therapy" represents an approach and slogan that has already been used by the industry in this context with airpolishing. However, if one thinks a bit further and refers to the underlying terminology (GBR/GTR), one should perhaps rather speak of "Guided Biofilm Regeneration." According to this, not only the mechanical cleaning but also the repopulation could be conceptually "controlled."

\section{DIAGNOSTICS AND ECOLOGIC BALANCE}

Adequate diagnostics is also a basic prerequisite. The actual periodontal classification provides for patient-oriented pointof-care diagnostics and in the future, tests immunological, and microbiological approaches including monitoring should be increasingly considered (10). Finally, probiotics, antiinflammatory, and possibly dietary considerations are of interest in the context of controlled re-colonization in order to modify the pocket environment (11). In short-biofilm management will probably not only pursue mechanistic considerations in the future, but will also increasingly take into account the establishment of a healthy oral flora on an interdisciplinary basis.

Perhaps we will soon experience a symbiotic "revolution" or co-evolution in this context. While after the initial euphoria in the post-war antibiotics era statements such as "Almost all experts agree that viral and bacterial infections will be eradicated by the year 2000" (Time Magazine, February 25, 1966), today it seems that the evidence is changing and new challenges have developed. The future of cause-related therapy will be challenged ....

\section{WHERE ARE WE TODAY-WHERE DO WE GO?}

If we look where we stand today, various critical remarks remain. For example, periodontitis remains undetected or misdiagnosed in too many cases, and treatment, even in the 21st century, is still mainly based on direct cause-related strategies, which are based on influencing the pathological agent(s), for example by removing hard and soft bacterial deposits, but the host and related immunologic factors are not routinely considered yet in the routine treatment regimen, with few exceptions maybe. Undoubtedly, a plethora of new studies including different clinical approaches and materials are published every month, very few of them really find their way into daily practice. Mostly, monotherapies are examined. Unfortunately, combination strategies often receive too little attention. This is probably also due to the fact that it is difficult to prove the most effective treatment steps for a complex topic such as periodontitis and the many influencing factors anyhow.

\section{GATHERING NEW KNOWLEDGE-A DIFFICULT TASK}

Attempts to summarize the available evidence in systematic reviews and to publish generally valid decision-making aids are also well-intentioned, but if one is critical and honest, the available evidence remains unfortunately often inadequate and based on a few studies only, some of which are of low quality (12). Therefore, the sad conclusion is practically always the same and unanimous that further well-conducted studies are necessary to draw definitive conclusions... This is not meant as criticism. We all know how complex, expensive and lengthy clinical studies are. Therefore, an important aspect in the future must be the comparability and standardization of clinical studies. And research should be coordinated and harmonized: Experts should not only meet to discuss existing evidence, but also to prospectively discuss research efforts. Importantly, the evaluation of the efficacy and efficiency of treatment modalities mostly measures differences. But the individual patient does not need respective statistical estimates, but clear clinical parameters and reference values (13). What does a difference of one millimeter or 12 percent really mean in most contexts? For whether an intervention is successful or not is not always manifested in a measured difference to a control treatment or even gold standard, but is expressed in the individual achievement of success or failure parameters. Future studies and reviews should also focus on this.

\section{LET US WORK ...}

While many journals are filled with outstanding and interesting laboratory and pre-clinical studies also at a molecular level, which investigate the understanding of various biological processes, they unfortunately often have only limited clinical relevance and will never be implemented in a clinical context. Although the aim of "Frontiers in Dentistry" and the Section Periodontics is to cross boundaries in the field and discover new things, the focus should always be on clinically applicable issues and a clear focus should be based on a corresponding hypothesis from which our patients can benefit in one way or another-sooner or later. Frontiers in Dentistry, invites researchers to submit their innovative work and contribute to the improvement of periodontal and systemic health.

\section{AUTHOR CONTRIBUTIONS}

PS conceived and wrote the manuscript. 


\section{REFERENCES}

1. Petersen PE, Ogawa H. Strengthening the prevention of periodontal disease: the WHO approach. J Periodontol. (2005) 76:2187-93. doi: 10.1902/jop.2005.76.12.2187

2. IDF Diabetes Atlas, 9th Edition. (2019). Available online at: https:// diabetesatlas.org/en/

3. World Cancer Report. (2014). Available online at: http://publications.iarc. fr/Non-Series-Publications/World-Cancer-Reports/World-Cancer-Report2014

4. Preshaw PM, Bissett SM. Periodontitis and diabetes. Br Dent J. (2019) 227:577-84. doi: 10.1038/s41415-019-0794-5

5. Hegde R, Awan KH. Effects of periodontal disease on systemic health. Dis Mon. (2019) 65:185-92. doi: 10.1016/j.disamonth.2018.09.011

6. Lorenzo D, GianVincenzo Z, Carlo Luca R, Karan G, Jorge V, Roberto M, et al. Oral-gut microbiota and arthritis: is there an evidence-based axis? J Clin Med. (2019) 8:1753. doi: 10.3390/jcm8101753

7. Adler CJ, Dobney K, Weyrich LS, Kaidonis J, Walker AW, Haak W, et al. Sequencing ancient calcified dental plaque shows changes in oral microbiota with dietary shifts of the Neolithic and Industrial revolutions. Nat Genet. (2013) 45:450-5, 455e1. doi: 10.1038/ng.2536

8. Diaz PI, Valm AM. Microbial interactions in oral communities mediate emergent biofilm properties. J Dent Res. (2020) 99:18-25. doi: $10.1177 / 0022034519880157$

9. Dahlhausen KE, Doroud L, Firl AJ, Polkinghorne A, Eisen JA. Characterization of shifts of koala (Phascolarctos cinereus) intestinal microbial communities associated with antibiotic treatment. PeerJ. (2018) 6:e4452. doi: $10.7717 /$ peerj.4452
10. Caton JG, Armitage G, Berglundh T, Chapple ILC, Jepsen S, Kornman $\mathrm{KS}$, et al. A new classification scheme for periodontal and peri-implant diseases and conditions - Introduction and key changes from the 1999 classification. J Periodontol. (2018) 89(Suppl. 1):S1-8. doi: 10.1002/JPER.1 8-0157

11. Matsubara VH, Bandara HM, Ishikawa KH, Mayer MP, Samaranayake LP. The role of probiotic bacteria in managing periodontal disease: a systematic review. Expert Rev Anti Infect Ther. (2016) 14:643-55. doi: 10.1080/14787210.2016.1194198

12. Kane RL, Butler $\mathrm{M}, \mathrm{Ng} \mathrm{W}$. Examining the quality of evidence to support the effectiveness of interventions: an analysis of systematic reviews. BMJ Open. (2016) 6:e011051. doi: 10.1136/bmjopen-2016-0 11051

13. Kolakovic M, Held U, Schmidlin PR, Sahrmann P. An estimate of pocket closure and avoided needs of surgery after scaling and root planing with systemic antibiotics: a systematic review. BMC Oral Health. (2014) 14:159. doi: $10.1186 / 1472-6831-14-159$

Conflict of Interest: The author declares that the research was conducted in the absence of any commercial or financial relationships that could be construed as a potential conflict of interest.

Copyright (c) 2020 Schmidlin. This is an open-access article distributed under the terms of the Creative Commons Attribution License (CC BY). The use, distribution or reproduction in other forums is permitted, provided the original author(s) and the copyright owner(s) are credited and that the original publication in this journal is cited, in accordance with accepted academic practice. No use, distribution or reproduction is permitted which does not comply with these terms. 